\title{
Aproximación semiótica para la interpretación del cementerio de Riobamba
}

\author{
Semiotic approach for the interpretation of the Riobamba \\ cemetery
}

José Miguel Ocaña Morales. ${ }^{1} \&$ Raúl Edison Lomas Badillo. ${ }^{2}$

DOI: $\underline{\text { https://doi.org/10.33262/visionariodigital.v3i2.481 }}$

\section{Resumen}

Este artículo se propone mostrar, el valor patrimonial y representación simbólica de la arquitectura funeraria del Cementerio de Riobamba, a partir del análisis semiótico que tiene como objeto analizar los elementos históricos y patrimoniales identificados en mausoleos, nichos, tumbas y estructura arquitectónica. Para su análisis se utilizó el método semiótico que permitió identificar las características trascendentales de los elementos funerarios existentes en el campo santo objeto de estudio, y sociológico mediante la aplicación de cuestionarios dirigidos a especialistas y población para evidenciar los hábitos e interacciones socio-culturales. Se comprobó que el Cementerio de la ciudad de Riobamba, Ecuador cuenta con suficientes elementos semióticos que enriquecen este espacio público de interacción y construcción socio-cultural, donde se desarrollan procesos permanentes de comunicación simbólica explicitas de creencias y memorias colectivas generacionales, que permitirín proyectarse al desarrollo de turismo cultural debido a su gran potencial patrimonial y semiótico.

Palabras Clave: Riobamba, Cementerio, Construcción Social, Cultura, Semiótica.

\footnotetext{
${ }^{1}$ Universidad Nacional de Chimborazo, Facultad de Ciencias Políticas y Administrativas, Comunicación Social, Riobamba, Ecuador, mocana@unach.edu.ec

${ }^{2}$ Universidad Nacional de Chimborazo, Facultad de Ciencias Políticas y Administrativas, Comunicación Social, Riobamba, Ecuador, rlomas@unach.edu.ec
} 


\section{Abstract}

This article aims to show the patrimonial value and symbolic representation of the funeral architecture of the Riobamba Cemetery, based on a semiotic analysis that aims to analyze the historical and patrimonial elements identified in mausoleums, niches, tombs and architectural structure. For its analysis, the semiotic method was used to identify the transcendental characteristics of the funerary elements existing in the holy field under study, and sociological through the application of questionnaires addressed to specialists and the population to demonstrate socio-cultural habits and interactions. It was proved that the Cemetery of the city of Riobamba, Ecuador has enough semiotic elements that enrich this public space of interaction and socio- cultural construction, where permanent processes of symbolic communication are developed explicit beliefs and generational collective memories, which would allow to project to the development of cultural tourism or due to its great patrimonial and semiotics potential.

Keywords: Riobamba, Cemetery, Social Construction, Culture, Semiotics.

\section{Introducción}

Un cementerio es algo más que un repositorio de cadáveres. Es lugar donde está presente de manera inobjetable la omnipresencia del tiempo, la maravillosa obra humana convertida en piedra y levantada como un elocuente y magnífico monumento diverso y multiforme capaz de inducir a la reflexión colectiva y al conocimiento (Vento, 2002). Estos sitios, monumentos y elementos funerarios constituyen un caso particular, poco valorado y menos atendido del patrimonio cultural material e inmaterial.

Los cementerios representan espacios de "memoria habitada" de nuestra sociedad (Barberán, 2005). En estos lugares y desde la antigüedad, las personas de diversas culturas han demostrado respeto a sus muertos, a través de rituales y costumbres propias de cada región. Para Thompson (2014), visitar un cementerio es mantener latente el recuerdo de seres queridos, y todo lo que se recuerda se mantiene vivo en el medio social.

"La comunicación humana se realiza por medio de acciones expresivas que funcionan como señales, signos y símbolos" (Leach, 1976, p.14). En los cementerios se hace visible todo lo que el hombre representa como un signo funerario, relacionados directa o indirectamente con la muerte, que son relevantes, significativos y forman parte de la identidad cultural de una sociedad. "El análisis semiológico, es preciso enfocar, no solo desde el punto de vista de la composición de aquello que es tomado como signo, sino que también es imprescindible ubicarlo en el medio circundante de ese signo, o sea, de su entorno" (Monroy de Ortega, 1983, p.23). 
Sin duda, es uno de los espacios sociales de mayor confluencia semiótica, aunque habitualmente se ubicaban fuera de la ciudad de los vivos. Su valor simbólico tiene tanto una dimensión tangible como intangible, pues en ellos convergen diversos significados históricos, sociales, artísticos, científicos, arquitectónicos, simbólicos, económicos y políticos, así como de diversidad cultural y religiosa, de tradiciones, usos y costumbres, entre otros. Los cementerios son parte del "Patrimonio Cultural", es decir "el conjunto de bienes tangibles e intangibles, que constituyen la herencia de un grupo humano, que refuerzan emocionalmente su sentido de comunidad con una identidad propia y que son percibidos por otros como característicos" (DeCarli, 2006, p. 5).

En los cementerios se concreta, expresa y visibiliza todo lo que el hombre representa como signo, especialmente respecto a todos aquellos aspectos relacionados directa o indirectamente con la muerte (Finol \& Fernández, 1995-1996). En este sentido los cementerios son "El conjunto de los rasgos distintivos espirituales y materiales que caracteriza a una sociedad y que abarca, además de las artes y las letras, los modos de vida, las maneras de vivir juntos, los sistemas de valores, las tradiciones y las creencias." (Pérez, 2014, p. 15).

El acercamiento a estos espacios patrimoniales debe concebirse desde una perspectiva integral, como un todo interrelacionado en el que los distintos elementos que lo componen cobran sentido al ser interpretados dentro del contexto global. Esta aproximación debe poner de manifiesto las superposiciones existentes entre los aspectos materiales e inmateriales, sus transformaciones, así como los significados y problemáticas actuales en relación a su reconocimiento y gestión.

Navarro \& Ortiz (2015) señalan que es necesario establecer un seguimiento sincrónico de las transformaciones que sufren los signos, en este caso en los cementerios, bajo una posible dinámica cultural lo que ayer significaron ciertos espacios, hoy podrían suponer nuevas significaciones.

A pesar de lo señalado hasta ahora, es escaso el interés prestado desde la antropología social ecuatoriana para el estudio de la significación y representación simbólica que tienen los espacios funerarios. El objetivo principal de esta investigación es estudiar la significancia y representación simbólica que tienen estos espacios socio-culturales como del cementerio general de la ciudad de Riobamba (Ecuador). Entre cuyos aspectos patrimoniales se destacan los aspectos históricos, socio-culturales y arquitectónicos, espacios monumentales y singulares de la sociedad que constituyen valores materiales e inmateriales que representan la memoria colectiva y de construcción social. "Desde el punto de vista semiótico se comprende al hecho arquitectónico como un signo de características sociales que emiten mensajes, textos y discursos, profundizando en su clasificación, procesos generativos, así como en sus probables resultados" (González \& Berenguer, 2015, p. 3).

Los cementerios son espacios que se vuelven un repositorio de la memoria social que requiere ser analizado, revisitado y reinterpretado en base a las nuevas prácticas socioculturales, por eso este trabajo ofrece un marco teórico elaborado a partir de 
concepciones semióticas que posibilitan formular un marco analítico adecuado para ser aplicado a espacios como los cementerios. En tal sentido, la semiótica asume el estudio de aquella relación de las personas con la muerte. Los panteones se convierten en una nueva forma de relación social, son símbolos de permanencia de los que ya no están. Se adquiere de manera indirecta una forma peculiar de trascendencia, lo que implica también pensar que los cementerios deben rastrear las dinámicas culturales de sus respectivas ciudades.

\section{Marco Referencial}

"La semiótica es la disciplina que estudia las relaciones entre el código y el mensaje, y entre el signo y el discurso" (Eco, 1973, p. 19). En tal consideración este estudio intenta explicar cómo se produce y capta el sentido (Greimas, 1949). Dado que los significados se producen mediante el contacto de los sentidos con materias expresivas comunicativas, significantes que representan bajo cánones socioculturales ciertos significados establecidos. Señalamos que es materia porque la producción y recepción del sentido necesita de un trabajo expresivo realizado sobre soporte material (Serrano, 1982). Ferdinand de Saussure es uno de los primeros autores que se refería a la semiología como: "Una ciencia que estudia la vida de los signos en el seno de la vida social" (Zechetto, 2002, p. 7). Y define además al signo como una entidad biplánica compuesta por dos caras, el significante que es el soporte material y el significado la imagen mental.

Por su parte Charles Peirce (1974), se refiere a la semiótica como la doctrina de la naturaleza esencial y de las variedades fundamentales de cualquier clase posible de semiosis (...) Por semiosis entiendo una acción, una influencia que sea, o suponga, una cooperación de tres sujetos, "Representamen la representación de algo, o sea es el signo como elemento inicial de toda semiosis" (Zechetto, 2005, p. 57). "Objeto es aquello a lo que alude el representamen y dice Pierce, este signo está en lugar de algo: su objeto" (Zechetto, 2005, p.59). Y el interpretante: es lo que produce el representamen en la mente de la persona. En el fondo es la idea del representamen, o sea del signo mismo. Pierce dice que "un signo es un representamen que tiene un interpretante mental.' (Zechetto, 2005, p.58).

Los signos dentro del contexto de la investigación, análisis semiótico de los cementerios se manejan a través de dos reglas.

"Primera: Los signos no se pueden presentar aislados. Un signo es siempre miembro de un conjunto de signos contrastados que funcionan dentro de un contexto social específico. Segunda: Un signo sólo transmite información cuando se combina con otros signos y símbolos del mismo contexto" (Leach, cit. por Bernal 2013, p.27).

La percepción del mundo como interpretación no es sino un acto de adscripción a un patrón de categorías perceptuales organizadas sobre esquemas básicos de representación intersubjetivamente constituidos reconocido como construcción social, los cuales 
ordenan las secuencias de experiencias en síntesis reticulares con arreglo a formas de sentido global que sostienen un mundo de vida: las creencias, actitudes y disposiciones mentales, atravesadas por valores de una sociedad o grupo social, en un espacio y tiempo determinados. (García, 1999 cit. por Asenjo et al. 2004, p. 1) menciona: “(...) modifica, transforma, significa o perpetua. Llena su entorno con signos que cumplen la finalidad de comunicar sucesos, experiencias vividas, historias personales, comunitarias o públicas, que adquieren sentido más allá de un aquí y ahora, y que necesitan continuas reinterpretaciones para poder explicar y dar cuenta de aquello que aconteció y sigue sucediendo".

El signo como referente de cultura, según (Eco, 2005) tiene dos aspectos fundamentales, primero el convencimiento de que todo concepto filosófico, expresión artística y manifestación cultural, deben situarse en su ámbito histórico; y, en segundo lugar, la necesidad de análisis semiótica que permita interpretar cualquier fenómeno cultural como un acto de comunicación regido por códigos.

Los espacios son un marco de vida para el ser humano, en donde desarrolla su cotidianidad; las formas urbanas como: calles, monumentos, barrios, cementerios cada uno con su diseño y arquitectura, la distribución espacial, generan significados complejos vinculados con lo histórico, lo ideológico y ligados al factor económico.

"La ciudad es un artefacto complejo creado por el hombre en su práctica social, su gestación es un proceso multidireccional, al comprender en sí la evolución social de diversas culturas urbanas contiene también la historia, la acumulación de tradiciones, vivencias, objetivos y aspiraciones de las comunidades". (Segre, 1997, p. 117).

"Los imaginarios urbanos estudian las culturas ciudadanas y que sus investigaciones avanzan hacia la construcción de una teoría del sentir ciudadano como expresión de deseos y hechos colectivos por su coincidencia en la búsqueda del mismo objeto. En rigor, son los imaginarios urbanos los que habitan a sus ciudadanos". (Silva, 2007, p. 91).

"La cultura hace posibles interacciones sociales que dan sentido a la vida de un grupo, que regulan nuestra existencia desde el momento mismo en que nacemos hasta cuando dejamos de ser parte de la sociedad si, nos llega la muerte, pero siempre seremos miembros de una sociedad y de una cultura" (Guerrero, 2002, p. 51-52).

(Navarro \& Ortiz, 2015, p. 7) mencionan que cultura es un "proceso social que implica necesariamente dinámicas de comunicación, es decir, interacción de diversos sistemas de significaciones estructuradas, que son a su vez capaces de producir nuevos y dinámicos sistemas de significados". En este sentido, en algunos contextos sociales, entre ellos los cementerios, con el paso del tiempo van transformando sus iniciales concepciones de sentido para los cuales fueron creados. El aporte de la semiótica a este tipo de situaciones se encuentra en la posibilidad de reconstruir la memoria de este tipo de tejidos sociales mediante el estudio de sus signos y significados. 
Entre los espacios señalados se destacan los cementerios. Ningún animal honra y entierra a sus muertos. (Heidegger, 1980) dejó dicho que el hombre es un ser para la muerte, pero también para después de la muerte. Sea como sea el animal humano es un ser trascendente y los primeros humanos lo expresaron ya muy tempranamente honrando a los muertos. Porque un muerto no es sólo un cadáver, un cuerpo inanimado (sin alma), es algo más, es un símbolo de algo que ha sido y con el que mantendremos de por vida un vínculo.

En definitiva, el cementerio se constituye en un espacio físico, "en contexto se define como el lugar y/o el espacio donde se reestablecen objetos, personas, acciones, entre otras, que cumplen un conjunto de semiosis múltiples" (Finol, 2004, p. 3). Es decir, son espacio geográfico que presenta la sintaxis dispuesta a ser leída con la ayuda de sistemas teóricos que permitan la comprensión de su estructura y su secuencia temporal en relación con otros acontecimientos, dándole al símbolo un valor de unidad de acción.

Los campos santos son lugares generadores de sentido de identidad a escala colectiva, posibilitando una reflexión que a futuro permita identificar otros fenómenos semióticos singulares y así ampliar su campo de investigación. Y situar a los cementerios como realidades que en su constitución general sean entendidas como sistemas de significación latentes en las pautas de comprensión del universo social que configura las identidades de los sujetos a nivel colectivo. (Maldonado, 2008)

En la cosmovisión andina el mundo de los muertos no es algo separado del mundo de los vivos. El hecho de morir no rompe los vínculos que había con la comunidad. Existe una comprensión cultural de la muerte, es bien asumida: así como nacemos, morimos. La muerte no es un tabú en Los Andes, ni se disimula el lugar de los muertos. Los rituales mortuorios, en la cultura andina, son muy ricos en simbolismo y muy complejos en su realización.

En la cosmovisión andina, también se cree en la vida después de la muerte, lo que hace pensar que los difuntos en el más allá requieren suplir algunas necesidades de la vida terrestre. Es así, que en la época de finados todavía se puede observar especialmente en el sector indígena que, a más de los arreglos de las tumbas, también llevan comida y bebida que fueron de especial agrado del difunto, para que en el otro mundo no sufran hambre o sed. Además, hay la creencia de que, al no realizar los rituales al difunto, este puede molestarse y convertirse en "alguien peligroso" (Janeta, 2015).

El presente trabajo de investigación aporta en la reconstrucción de la identidad cultural de los riobambeños, en la medida que el análisis semiótico de su cementerio plantea reconstruir el valor y significado de la muerte, en un espacio cargado de historia y significación que necesariamente deben ser repensados en la ciudad. Si partimos de la premisa que estos lugares místicos sufren de abandono físico y social, implica no reconocer en la práctica socio-cultural a estos escenarios como lugares generadores de historia y construcción social. 
El campo santo de Riobamba es una muestra a pequeña escala de los cambios que ha experimentado la ciudad desde su reasentamiento en 1797. El cementerio reproduce el trazado en cuadrícula de la ciudad hispanoamericana. El crecimiento poblacional de la ciudad provocó la expansión urbana y paralelamente del cementerio, en este espacio se encuentran diferentes estilos arquitectónicos que surgieron durante los siglos XIX, XX y en la actualidad se continúa manifestando una misma relación iconográfica entre la ciudad de los vivos y de los muertos.

El cementerio de Riobamba fue construido en el año 1900 y cuenta con una extensión actual aproximada de 5.800 metros cuadrados, la cobertura física entre nichos y tumbas es de 33.000 sitios para inhumar y ocupados casi en su totalidad.

El cementerio general guarda mucha historia y en sus sepulcros se encuentran personajes ilustres que fueron parte importante en la construcción de la sociedad riobambeña, como las primeras familias influyentes de la época enterradas en los cuatro imponentes mausoleos que se localizan a la entrada. En su entorno se hallan tumbas de poetas, músicos, pintores, políticos o humanistas. (Cáceres, 2010, p. 16) afirma: "todo 'textociudad' está inscrito en la reproducción social de formaciones históricas que han existido y existen". En tal razón podríamos decir que un cementerio es considerado como un sistema complejo de signos y símbolos.

En nuestro contexto no existe investigación alguna que analice e interprete la multiplicidad de signos y códigos que se encuentran en este sitio. Es oportuno un análisis semiótico de los diferentes componentes materiales e inmateriales patrimoniales del cementerio para poder valorar su historia y cultural como espacio de construcción social.

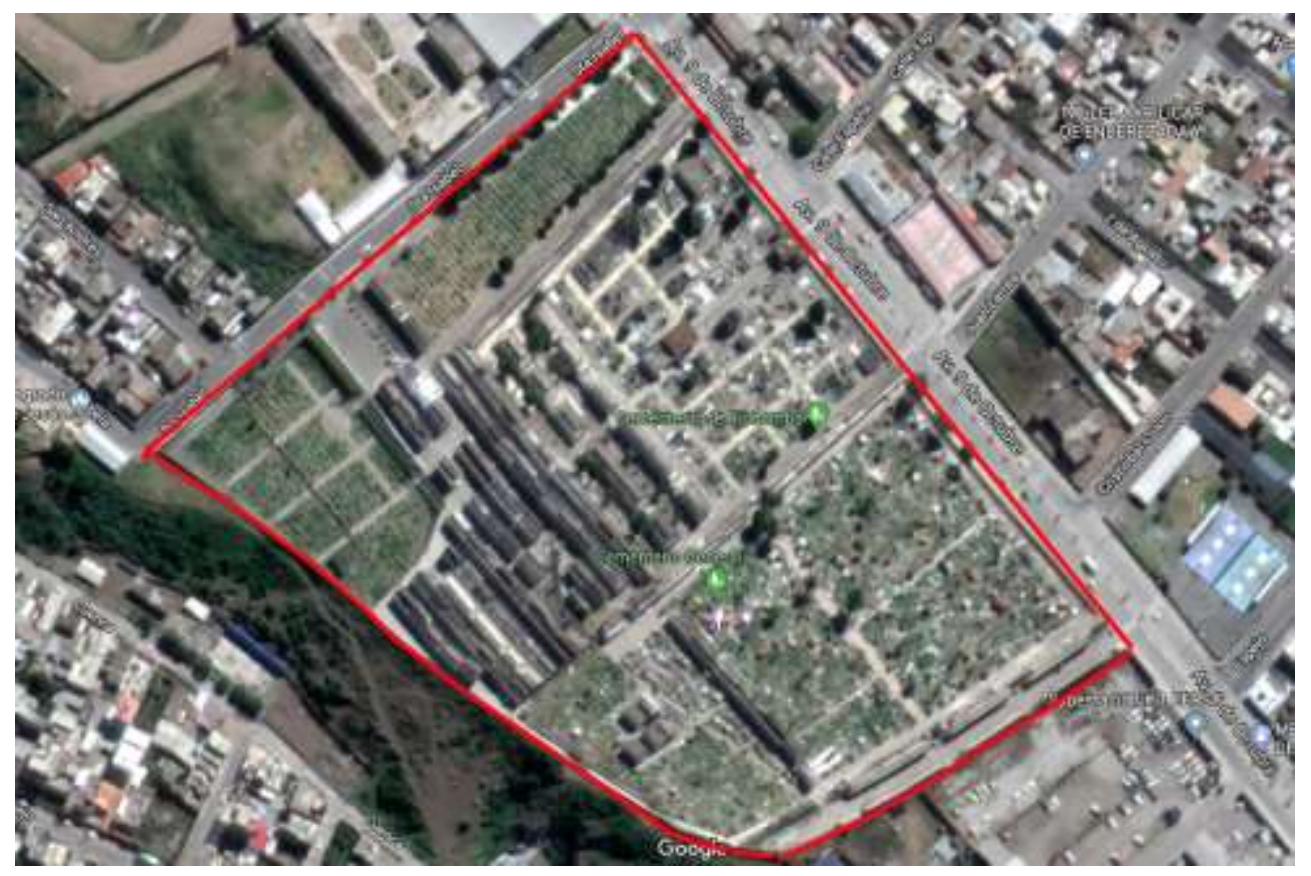

Fotografía 1: Mapa del Cementerio General de Riobamba. 


\section{Metodología}

Para la presente investigación se consideró la propuesta metodológica realizada por (Magariños, 2007) y referenciada por (Navarro \& Ortiz, 2015) donde se establece a la semiótica como método de interpretación y análisis de la realidad social:

"Yo defiendo la tesis de que la semiótica proporciona, en este momento de la historia del conocimiento científico (o, simplemente, riguroso), un enfoque y un conjunto de instrumentos que la sitúan como un método preciso y eficaz en el campo, al menos, de las ciencias sociales. La semiótica tiene la riqueza y la consistencia necesaria para acompañar la producción y la interpretación de sus múltiples aspectos teóricos y empíricos”. (Margariños, 2007, p. 1)

Desde lo planteado el presente artículo apunta a pensar que, en un sentido general, para analizar los procesos de interacción social y de sentido, así como de significación de los bienes materiales patrimoniales existentes, en este caso del cementerio porque siempre será necesario "re-semantizar los mensajes entre los seres humanos." (Navarro, 2011).

Adicionalmente se utilizó la metodología cuali-cuantitativa, a través del método científico que permitió conocer acerca del Cementerio General de Riobamba, mediante fundamentación teórica y la recolección de datos a partir de la aplicación de encuestas a la población; el método inductivo deductivo permitió realizar deducciones lógicas de los fenómenos observados; complementariamente se utilizó la metodología cualitativa, con entrevistas a expertos en el ámbito semiótico, cultural e histórico de los bienes patrimoniales materiales e inmateriales del cementerio en cuanto a su forma color y tipografía. Los cuestionarios se hicieron anónimamente, sin conocimiento, unos expertos de otros, y se realizó consenso entre las aportaciones de los participantes. También para contrastar y registrar los hábitos socio-culturales se realizó un análisis descriptivo y estadístico a la población que interactúa con el contexto del Cementerio de Riobamba, para así llegar a conocer las situaciones, costumbres y actitudes predominantes de la colectividad.

A nivel de la delimitación de la muestra a analizar semióticamente, se realizó una selección de 113 unidades de las materias expresivas simbólicas existentes en el cementerio, como mausoleos, lápidas, tumbas, nichos y construcciones arquitectónicas.

Se realizaron entrevistas, mediante la aplicación de cuestionario a especialistas en el ámbito semiótico, cultural e histórico; y encuestas a 400 personas seleccionadas en función a una muestra representativa, obtenida de una población de 157.780 habitantes según el INEC 2010, la misma que fue dirigida exclusivamente a los habitantes de Riobamba urbano, quienes pudieron verter opiniones y posiciones en relación a los hábitos socio-culturales desarrollados en el contexto del cementerio. 


\section{Resultados y Discusión}

\section{Análisis semiótico de expertos}

De la muestra de 113 materiales expresivos entre mausoleos, tumbas, nichos y construcciones arquitectónicas del Cementerio de Riobamba se presentaron y consultaron con un grupo de expertos en semiótica, cultura e historia de la ciudad de Riobamba, mediante entrevistas que sirvieron para consensuar las respuestas e interpretaciones semióticas. Los expertos seleccionados fueron Guillermo Montoya, presidente de la Casa de la Cultura de Chimborazo; Franklin Cepeda Astudillo, historiador; y Rafael Salguero, semiólogo. Quienes describieron a modo de resumen los elementos expresivos simbólicos, enfocados en la forma, color y tipografía que aparece en los símbolos y otros signos que sirvieron para la aplicación del método semiótico (Navarro \& Ortiz, 2015).

De los cuestionarios realizados a expertos y del consenso de los mismos se obtuvieron las aportaciones complementarias y consensuadas siguientes.

En el contraste anónimos de sus respuestas y aportaciones coinciden en señalar elementos comunes en el simbolismo, valor patrimonial y cultural que representan los objetos existentes en el lugar. También coinciden en el sentido y significación que tienen estos centros como esencia de la vida, historia, cultura y religión, y cómo son ahora parte de la identidad de los pueblos mestizos y andinos, que se han convertido en espacios públicos de comunicación, interacción y construcción social, como lo ratifica (DeCarli, 2006, p. 5) al señalar que "el conjunto de bienes tangibles e intangibles constituyen el patrimonio cultural de los pueblos".

A criterio de Montoya, el simbolismo del cementerio tiene la representación del recuerdo, admiración de personajes ilustres y sobre todo el amor a quienes ya no están entre nosotros, pero dejaron su huella al pasar el umbral existencial. Cepeda cree que las ciudades tienen su espejo en los cementerios, refiere que, si se quiere conocer una ciudad, el mejor referente es el cementerio y en el caso de Riobamba, donde existe una hibridación de lo antiguo con lo moderno, perdiendo la posibilidad de convertirle al cementerio en una necrópolis, como reflejo de una ciudad ilustrada. Salguero dice que cuando hablamos de simbolismo hay que partir de la concepción de los riobambeños de su alto apego a las tradiciones religiosas, es así que, el cementerio constituye un punto simbólico importante para la ciudad, ya que hay muchas personas que van a visitar a sus familiares y depositan elementos simbólicos que tratan de mantener vivos los recuerdos de quienes ya no están. Es posible entender entonces, que en estos lugares se activan los vínculos de identidad construidos en la proyección temporal en relación a diversos códigos culturales presentes en el proceso de encuentro entre el ser vivo y la memoria fuerte del ser muerto, definida como: "una memoria masiva, coherente, compacta y profunda (...) Una memoria fuerte es una memoria organizadora, en el sentido de que es una dimensión importante de la estructuración de un grupo y, por ejemplo, de la representación que éste va a hacerse de su propia identidad" (Candau, 2001, p. 40) 
En cuanto a la representación simbólica de las estructuras arquitectónicas que yacen en el cementerio, Montoya relata que hay tres edificaciones que son muy importantes que destacan, aparte de otras estructuras comunitarias. Cepeda expresa que en la parte central y las más antigua del cementerio se puede observar una división arquitectónica, como un museo, un jardín y también encontramos figuras simbólicas muy características de mausoleos familiares apegados a ciertas doctrinas o creencias. Salguero menciona que en el cementerio no se ve una estructura arquitectónica homogénea por diferencias de estratos sociales, además que se puede observar elementos de la "Masonería". Los especialistas destacan que, en el Cementerio de Riobamba existe una arquitectura funeraria que de algún modo replica a la ciudad urbana como lo confirma (Benavente, 1997) "éstas son una muestra a pequeña escala de sucesivos estilos escultóricos y arquitectónicos que emergen contemporáneamente en la ciudad, manifestándose casi como una forma de copia falsa en la ciudad de los muertos".

En relación a la representación semiótica de las figuras, símbolos y signos de lápidas como en bóvedas, Montoya enuncia que la parte estructural de mausoleos, de criptas especiales con rasgos muy particulares con figuras culturices especiales, corresponde a mediados del siglo XX, donde había cierta actitud de conmemorar a los difuntos con elementos alegóricos muy representativos como ángeles, coronas y tumbas con formatos especiales. Cepeda por su parte describe que el significado obedece a sistemas de convenciones y representaciones subjetivas, encontramos imágenes de la Virgen, de Cristo, crucifijos cristianos, antorchas invertidas o cráneos que representan a la muerte. Salguero, declara que, la mayoría de las lapidas muestran elementos visuales que están ligados a personajes bíblicos de una tradición religiosa, que creen son seres protectores de las dimensiones no físicas; además destaca la presencia de corazones que representan un amor filial (de familia) y también un amor eros (de pareja). Todos los elementos de carácter artístico funerario religioso encontrados, corresponden a iconografías de hechos bíblicos y que en su mayor parte "representa el sacrificio de Cristo para salvar la humanidad" (Dorling, 2008, p. 178).

En relación a los elementos simbólicos más representativos identificados en el cementerio de Riobamba, Montoya dice que la parte de tumbas antiguas que cuentan con elementos escultóricos son los que más resaltan, pero también hay cierto tipo de lapidas que denotan un gran desarrollo artesanal en alto relieve y con retratos pintados a mano. Cepeda refiere a la similitud en el trazado de una ciudad apegado a la simetría hecho en las primeras décadas del siglo XX, cuando llegaron franceses al Ecuador. Salguero manifiesta que los principales elementos que encontramos son los querubines, el conjunto escultórico de ángeles y arcángeles que han sido estudiados a nivel del arte; hay que descartar el aspecto romántico por las figuras que están adornadas las bóvedas, es algo emocional por las imágenes y lo lingüístico que se complementa con lo iconográfico.

"Consecuentemente, puede verse que, el hombre no rechaza la realidad de la muerte, más lo aborda discreta y hasta con cierto temor, considerando que, en la trayectoria de la vida 
del ser humano, esta es una instancia por el que se transitará más bien a una nueva realidad" (Calvo, 2010, p. 7).

Y finalmente en relación de los elementos semióticos del cementerio con la identidad cultural del pueblo, todos los expertos consultados coinciden en señalar que hay una identidad compartida entre cultura y religión; sin embargo, Salguero puntualiza que, si hablamos de los elementos antropológicos, el cementerio no es parte de la identidad riobambeña porque fue impuesta por los españoles; y puede decirse que Riobamba es ecléctica una mezcla de lo republicano y lo gótico.

\section{Resultados de la encuesta y análisis estadístico:}

En el desarrollo de la investigación para la recopilación de información sobre el campo santo de Riobamba, se utilizaron las técnicas de la encuesta con la ciudadanía, partiendo de una muestra de 400 personas, gran parte de los ciudadanos consideran que el cementerio constituye un espacio público de construcción social, debido a su libre acceso, interacción y comunicación permanente que ahí se desarrolla, donde yacen los restos fúnebres de personajes ilustres; así mismo destacan la identidad cultural existente por sus simbolismos que representan los bienes patrimoniales materiales e inmateriales. Como se puede observar en la Tabla 1.

Tabla 1: Resultados de encuesta en la ciudadanía de Riobamba. Muestra: 400 encuestas

\begin{tabular}{|c|c|c|}
\hline CUESTIONARIO & SI & NO \\
\hline 1. ¿Con qué frecuencia visita usted el cementerio? & $81 \%$ & $19 \%$ \\
\hline 2. ¿Cree usted que el cementerio es un espacio público? & $75 \%$ & $25 \%$ \\
\hline $\begin{array}{l}\text { 3. ¿Conoce personajes ilustres que descansen en el cementerio de } \\
\text { Riobamba? }\end{array}$ & $85 \%$ & $15 \%$ \\
\hline $\begin{array}{l}\text { 4. ¿Considera que el cementerio constituye un espacio de } \\
\text { comunicación } \\
\text { e interacción? }\end{array}$ & $54 \%$ & $46 \%$ \\
\hline $\begin{array}{l}\text { 5. ¿Cree que el cementerio es parte de la identidad cultural de } \\
\text { Riobamba? }\end{array}$ & $60 \%$ & $40 \%$ \\
\hline $\begin{array}{l}\text { 6. ¿Conoce el simbolismo que representan los bienes patrimoniales, } \\
\text { materiales e inmateriales del cementerio? }\end{array}$ & $54 \%$ & $46 \%$ \\
\hline $\begin{array}{l}\text { 7. ¿Cree usted que la fe, cultura, arquitectura cementerial e } \\
\text { iconografía funeraria, hacen del Cementerio de Riobamba un } \\
\text { atractivo turístico? }\end{array}$ & $60 \%$ & $40 \%$ \\
\hline
\end{tabular}

\section{Elaboración Propia}

Guerrero (2002), refiere que los diferentes aspectos culturales nos permiten integrarnos a determinados grupos humanos durante toda nuestra vida, esta y las demás consideraciones hechas por los especialistas y personas encuestadas nos motivan a afirmar que el Cementerio General de Riobamba, se ha constituido en un espacio de interacción y construcción social, debido a que este lugar representa emociones, memorias y sentimientos que fomentan la unión familiar; estableciéndose como un área de interacciones sociales, más aun tomando en cuenta que el cementerio no solo ofrece 
lugares de descanso eterno; sino también en el interior se presentan rituales, serenatas, inhumaciones, eventos poéticos o literarios, etc.

\section{Análisis resumido de elementos y materiales expresivos simbólicos del Cementerio de Riobamba, según los expertos.}

La observación de los objetos simbólicos del cementerio, permitió encontrar muchos aspectos de carácter semiótico con una inmensa representación patrimonial, vinculada a la cultura moderna con fuerte influencia europea, pero que han pasado a formar parte de la identidad cultural de la sociedad riobambeña y el mestizaje. Estos lugares se de a poco se van convirtiendo en lugares públicos de construcción social que representan espacios de la "memoria habitada" de nuestra sociedad como lo sostiene (Barberán, 2005), siendo generadores de mitos, leyendas, costumbres, recuerdos, vivencias, historia y cultura, basados en las creencias religiosas, mitos y ritos muy arraigados al pueblo católico de la localidad.

Las evidencias encontradas en el cementerio, ver Figuras 1 a 7 , permitieron identificar el simbolismo, valor patrimonial y cultural que representan los objetos semióticos, pero fundamentalmente el simbolismo, sentido y significación que tienen estos centros como esencia de la vida, historia, cultura y religión, que ahora son parte de la identidad de la ciudad, convertido en espacios públicos de comunicación, interacción y construcción social.

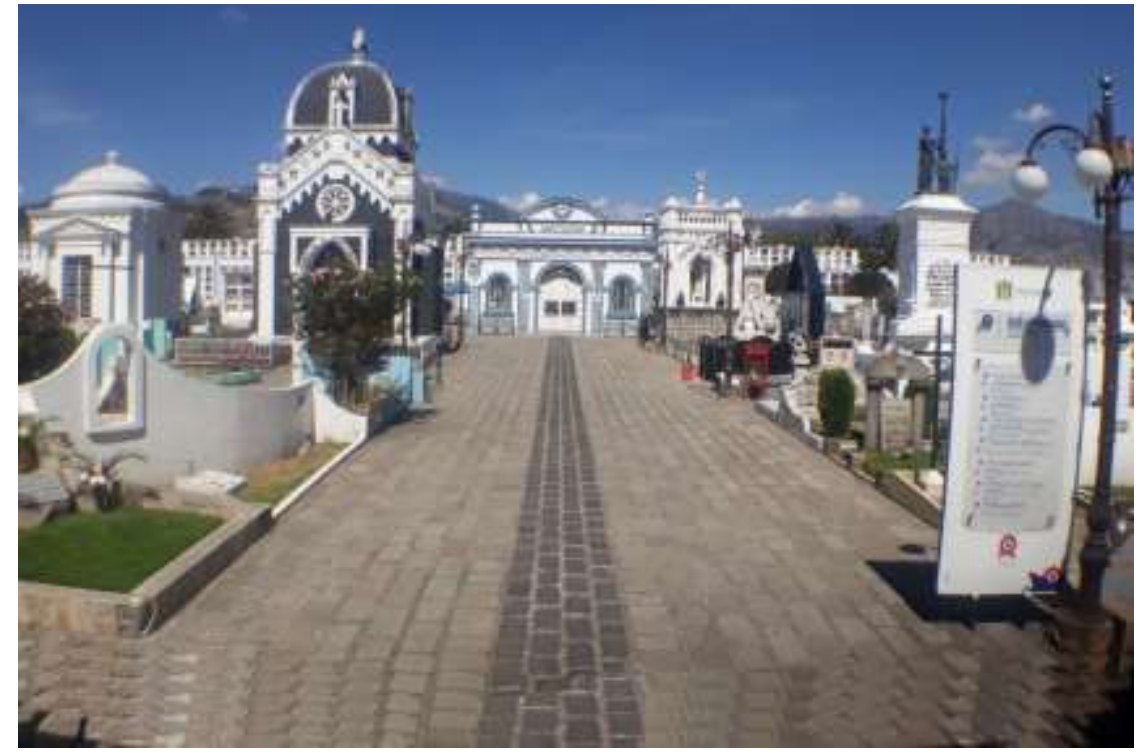

Fotografía 2: Entrada principal del Cementerio de Riobamba.

Elementos semióticos: Colores blancos, verdes, grises y negros, anfiteatro celeste pastel, e inscripciones de imprenta. La ciudad de los muertos al igual que de los vivos, en su entrada cuenta con una gran avenida principal en la que confluyen los más imponentes mausoleos y tumbas de importantes personalidades especialmente de la época republicana, desemboca en el anfiteatro construido bajo una línea arquitectónica europea por los hermanos Natale y Lucas Tormen; y en su derredor una serie de nichos que a manera de barrios pertenecen a diferentes instituciones $u$ organizaciones sociales. 


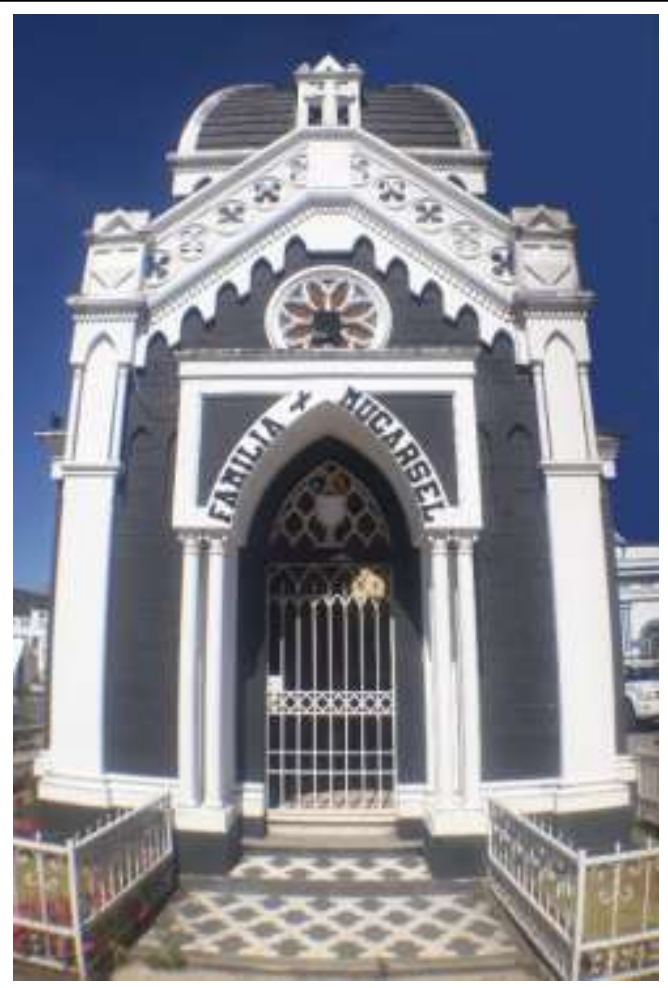

Fotografía 3: Mausoleo Familia Mucarsel

Elementos semióticos: Cúpula; Color blanco; Color negro; Letra imprenta; Cruz; Pilares. Éste mausoleo es uno de los más icónicos del cementerio, perteneciente a la familia Mucarsel construido en el año de 1950, los pilares representan sostenibilidad y fuerza. La cúpula honorabilidad y ponderación económica, el color blanco simboliza luz, bondad, pureza, virginidad, optimismo, perfección, inocencia, aislamiento y frio. El negro representa el misterio, tristeza y soledad, es el color de los ritos funerarios en la cultura occidental, se le asocia con tristeza, soledad, nostalgia, lágrimas, duelo, pero también la elegancia. La letra imprenta se utiliza como una manera de escritura clara y legible.

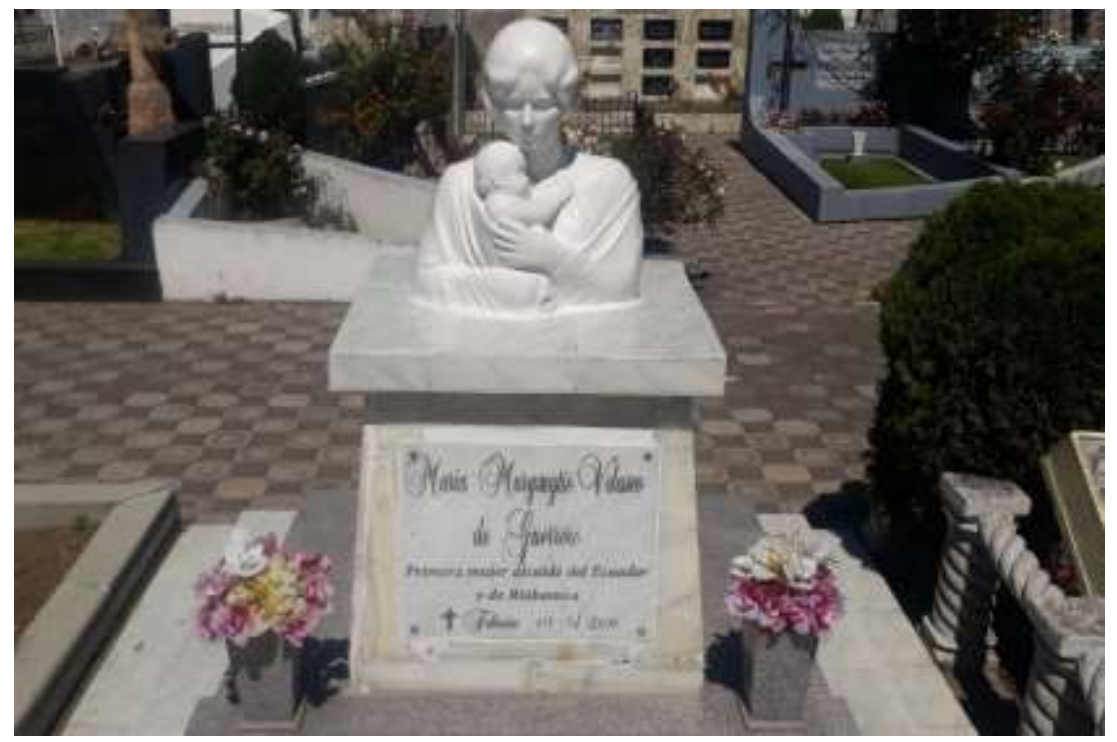

Fotografía 4: Busto de María Murgueitio de Guerrero. 
Elementos semióticos: Busto de una mujer con un bebé en brazos Color blanco, Inscripción Manuscrita. Éste busto pertenece a María Murgueitio de Guerrero, primera alcaldesa del Ecuador y de Riobamba. De acuerdo al criterio de Salguero, el color blanco representa la pureza, aporta paz y confort, alivia la sensación de desespero y de shock emocional, ayuda a limpiar y aclarar las emociones, los pensamientos y el espíritu. La letra manuscrita es utilizada como representación de elegancia en las lápidas; además de que el busto representa a la mujer en su aspecto protector de madre.

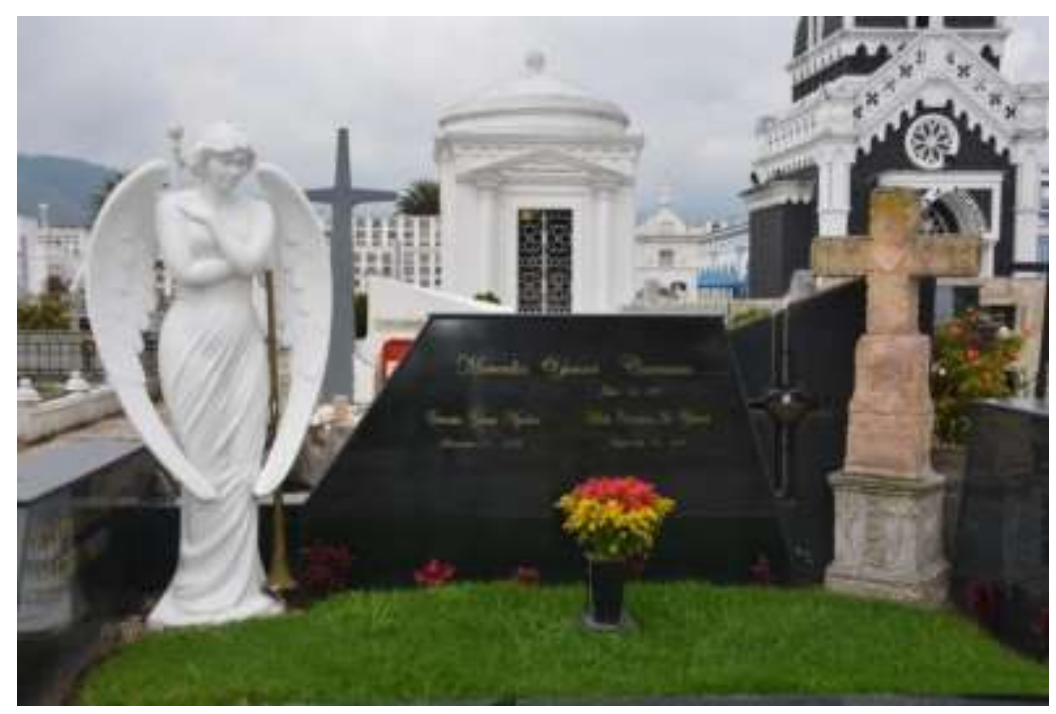

Fotografía 5: Lápida a la Madre

Elementos semióticos: Ángel, Cruz, Trompeta, Color negro, Color Blanco, Color Verde, Letra Manuscrita. Las leyendas urbanas dictan que, ésta escultura fue levantada en honor a una madre que perdió a su hijo a muy temprana edad. El ángel femenino con la trompeta representa la inocencia de una madre y la espera de la llegada de Dios; por ello está hacia abajo. La cruz es símbolo de religión católica o cristiana. La letra manuscrita es utilizada como representación de elegancia en las lápidas.

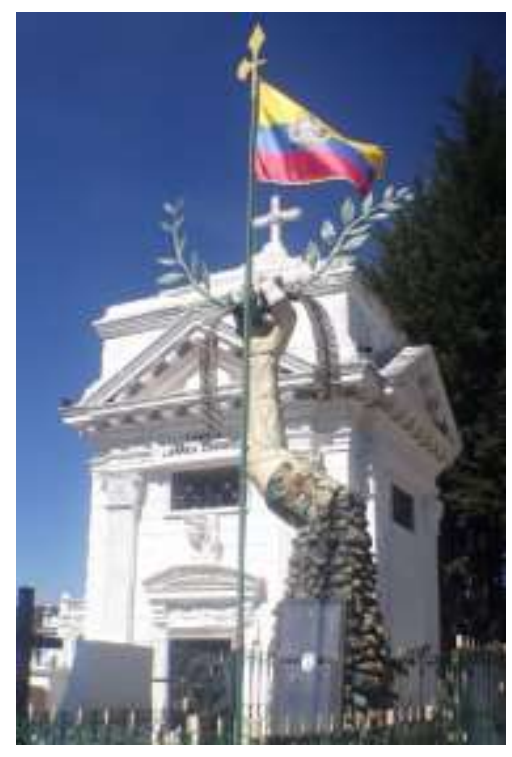

Fotografía 6: Héroe de la Guerra del Cenepa. 
Elementos semióticos: Hoja de laurel, Cinturón de balas, Brazo en alto, Bandera del Ecuador, Color verde y Letra imprenta. Ésta escultura es una de las más vistosas y hace honor al héroe que falleció en la Guerra del Cenepa. El color verde que predomina resulta relajante y refrescante, que incita a quién lo contempla a sensaciones de serenidad y armonía. Está íntimamente relacionado con todo lo natural, simbolizando también la vida, la fertilidad, la buena salud y la valentía. El cinturón de balas representa la vida militar y la caída de una persona en guerra. Las hojas de laurel son señal de fama, valor y grandeza alrededor del mundo; es sinónimo de historia, de tradición, de grandeza. El brazo en alto representa la valentía. La bandera tricolor enarbolada símbolo de una patria libre y soberana.

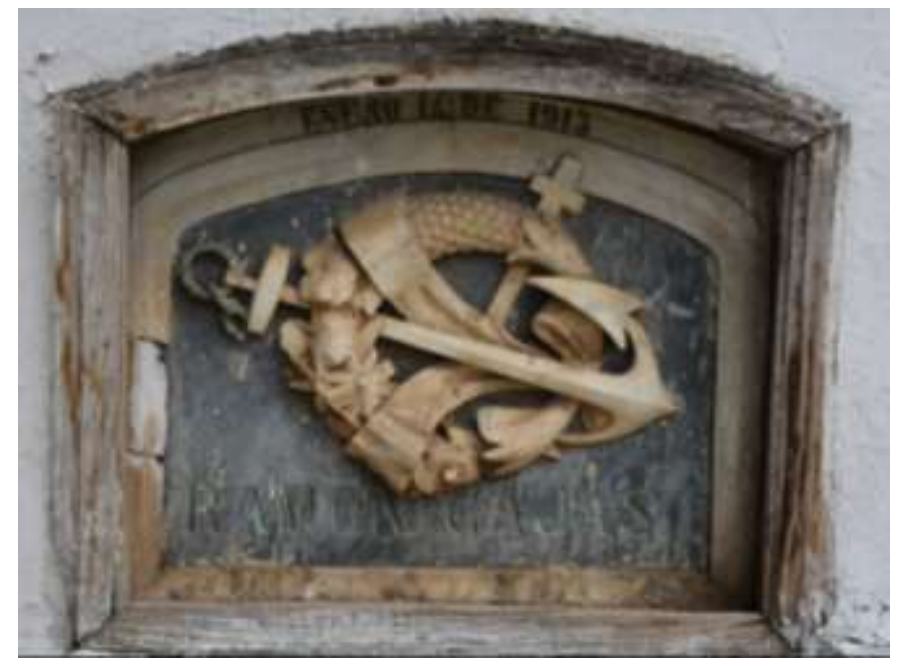

Fotografía 7: Lápida de Los Peces tallada en hueso.

Elementos semióticos: Color blanco; Color negro; Ancla atravesada con un pez y flores; Letra imprenta. No existe mayor registro sobre ésta lápida, sólo se conoce por su inscripción que corresponde a 1913 y fue tallada en hueso humano, posiblemente del fémur. En su contexto todos sus elementos se encuentran relacionados con el mar, el ancla símbolo de fe, esperanza en la resurrección y vida con Dios. El pez indica comunión con Cristo. Y las flores son similares a los corales.

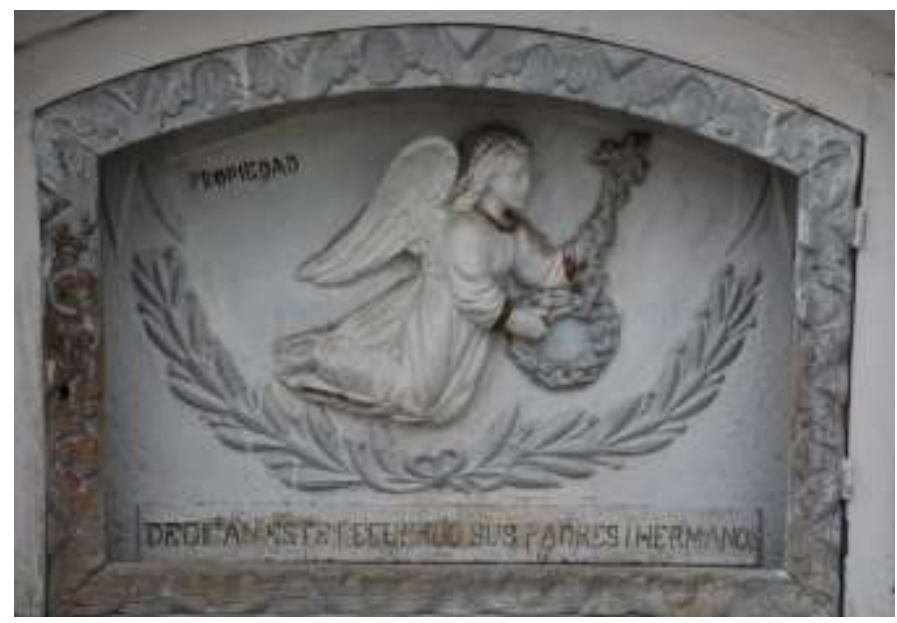

Fotografía 8: Lápida de ángel. 
Elementos semióticos: Hojas de olivo, Color dorado y blanco, Ángel con cadenas, Letra imprenta. No se tiene registro sobre ésta lápida que data de 1910. La rama de olivo símbolo de la paz. El color dorado es el atributo del bien y de lo bueno. El ángel con una cadena cerrada en su mano significa la llamada de Dios, en la creencia de poder llegar más rápido al cielo.

En el análisis semiótico realizado a los bienes patrimoniales materiales que constituyen la estructura arquitectónica del Cementerio General de Riobamba, se infirió que cada uno de los elementos existentes allí poseen un significado específico de acuerdo a la forma, color y tipografía; dado que, en términos generales todos los ángeles, cruces y peces tienen una representación de esperanza a la resurrección y encuentro con Dios; el color blanco evoca la paz, la pureza y la calma; el color negro es la elegancia y distinción, como también la tristeza y luto; además que la tipografía dominante es la letra manuscrita.

\section{Conclusiones}

- Tras el análisis semiótico efectuado a los objetos materiales y simbólicos que forman parte de la estructura arquitectónica del campo santo, se concluye que éstos tienen mucha relación con la historia, cultura y religión de los pueblos mestizos andinos, criterio que ha sido compartido por la ciudadanía y expertos consultados sobre el tema, quienes afirman que los objetos del cementerio son un valor patrimonial intangible con mucho sentido, significación e identidad cultural.

- Según el análisis semiótico realizado en la investigación de signos y símbolos de los objetos que se encuentran en el Cementerio de Riobamba, podemos mencionar que, cada uno de los elementos tienen un significado específico de acuerdo a la forma, color y tipografía; en general los ángeles, las cruces y los peces representan la esperanza de la resurrección en Dios; el color blanco evoca la paz, la pureza y la calma; el color negro es la elegancia y distinción; además que la tipografía dominante es la letra manuscrita.

- Concluimos que el Cementerio de Riobamba cuenta con una arquitectura funeraria con valor patrimonial muy importante de estilo europeo que data de inicios del siglo XX y antropológicos por la mezcla de lo republicano y lo gótico.

- Basado en el estudio científico, el análisis semiótico de especialistas y la opinión ciudadana, podemos concluir que el Cementerio de Riobamba cuenta con elementos patrimoniales y simbólicos representativos para proyectar un nuevo polo de desarrollo turístico cultural sustentable.

- "El turismo cultural es un tipo de actividad turística en la que la motivación esencial del visitante es aprender, descubrir, experimentar y consumir las atracciones / productos culturales tangibles e intangibles en un destino turístico" (Greg, 2018, p. 2). Estas expresiones socio- culturales se refieren a una serie de características espirituales y emocionales que abarcan, la arquitectura, el patrimonio histórico-cultural, patrimonio culinario, la literatura, la música, las 
industrias creativas y las culturas vivas con sus estilos de vida, creencias y tradiciones.

- El Cementerio de Riobamba, desde una visión socio-cultural no solo puede constituirse como un lugar sacrosanto, en donde se desarrollan rituales funerarios y religiosos únicamente, que sirven para despedir a los difuntos en su descanso eterno, sino también, se podría fortalecer actividades de carácter artístico-cultural para aprovechar la difusión del patrimonio funerario y proyectarse al desarrollo turístico.

- De acuerdo de (Greg, 2018), el interés por el turismo cultural creció durante los años 1980 y 1990, impulsada por el auge de la herencia (Hewison, 1987). El crecimiento de los viajes internacionales y nacionales y la identificación del turismo cultural como una forma de turismo que estimularía la economía y la cultura (Richards, 2001).

\section{Referencias bibliográficas}

Asenjo, B., Carrasco, G., Dougnac, P., Harries, E., Ovalle, M., Pi,entel, C. \& Solar, M. (2004). Cementerio General: Un espacio de representación de la memoria de la ciudad de Santiago. Universidad de Chile Instituto de la Comunicación e Imagen

Barberán, R. (2005). Patrimonio cultural funerario: Los cementerios de la minoría religiosas en España. Barcelona.

Benavente, A. (1997). Las vanidades en la iconografía funeraria chilena. Anales de la Universidad de Chile, Sexta Serie, Nº 6, diciembre de 1997.

Bernal, D. (2013). Semiótica de la comunicación Simbólica con los difuntos. Archivo de la Revista Comunicación, (30). 25-31. Medellín: Colombia.

Cáceres, M. (2010). Semiótica, Cultura y Semiótica de la Cultura. Entretextos-Revista Electrónica 16: 14-15-16. Recuperado de https://gracielasg.files.wordpress.com/2018/01/entretextos14-16.pdf

Candau, J. (2001). Memoria e Identidad. Ed. Del sol, Buenos Aires, Argentina.

Calvo, R. (2010). El histórico cementerio republicano (de la Almudena) y de cultura de la muerte Cusqueña. Cusco Perú: Alpha Servicios Gráficos SRL

DeCarli, G. \& Tsagaraki, C. (2006). Un Inventario de Bienes Culturales: ¿por qué y para quién? Instituto latinoamericano de Museos. San José, Costa Rica: ILAM. Recuperado de http://www.ilam.org/viejo/ILAMDOC/IBC-porqueYparaquien.pdf [Consulta: julio 2016]

Dorling, K. (2008). Signos y símbolos. China: Dorling Kindersley

Eco, U. (1973). Signo. Madrid: Labor.

Eco, U. (2005). Tratado de semiótica general. México. 
Finol, J. \& Fernández, K. (1995-1996). Socio - semiótica del rito: predominio de lo femenino en ri-tuales funerarios en cementerios urbanos. Morphé No 13 / 14 (Julio 95 / junio 96). Puebla, México, p. 303 - 318.

Finol, J. \& Montilla, A. (2007), Rito y Símbolo: Antropo-Semiótica del velorio en Maracaibo.

Google. (s./f.). [Mapa del Cementerio de Riobamba, Ecuador en Google maps]. Recuperado el 11 de Mayo, 2019, de https://www.google.com/maps/@-1.6800257,$78.6577591,327 \mathrm{~m} / \mathrm{data}=! 3 \mathrm{~m} 1 ! 1 \mathrm{e} 3$

Gonzáles, C. \& Berenguer, J. (2015). Semiótica y objetos arquitectónicos: Aspectos teóricos $y \quad$ metodológicos. http://www.revista180.cl/index.php/revista180/article/viewFile/18/16

Greimas, A. (1980). Semiótica y ciencias sociales. Buenos Aires.

Greg, R. (2018). El turismo cultural: Una revisión de investigaciones recientes y las tendencias. Diario de Hostelería y Turismo de Gestión 37(36)

Guerrero, P. (2002). La cultura, estrategias conceptuales para entender la identidad, la diversidad, la alteridad y la diferencia. Quito.

Heidegger, M. (1980). Ser y tiempo. México D.F.

Hewison, R. (1987). La industria del patrimonio: Gran Bretaña en un clima de decadencia. Londres: Methuen.

Janeta, P. (2015). Cosmovisión y Sabiduría Puruwa. Riobamba: Offset.

Leach, E. (1976). Cultura y comunicación: la lógica de la conexión de los símbolos. Madrid: Siglo XXI.

Margariños, J. (2007). Manual de estudios semióticos. Recuperado de file:///C:/Users/Boss_T/Desktop/CEMENTERIO/ManualSemioticians-1999-2007.pd

Monroy de Ortega, L. (1983). Acercamiento a una semiología de la imagen. Signo Y Pensamiento, 2(2), 21 - 26. Recuperado a partir de http://revistas.javeriana.edu.co/index.php/signoypensamiento/article/view/5816 Navarro, L \& Ortiz, J. (2015). Una propuesta teórica para el análisis semiótico de los cementerios de Barranquilla (Colombia). Recuperado de

file://C:/Users/Boss_T/AppData/Local/Temp/5791-11766-1-SM.pdf

Navarro, L. (2011). ¿Para qué sirve la semiótica? Una propuesta de resignificación de la Mujer a través de la comunicación para el cambio social. Revista de Investigación y desarrollo, 19 (1), 166-195.

Peirce, Ch. (1974). La ciencia de la semiótica. Estados Unidos. 
Pérez, L. (2014). Turismo Cultural: Una oportunidad para el desarrollo local. Guía Metodológica. Santiago, Chile: Servicio Nacional de Turismo.

Revista de Ciencias Humanas y Sociales. [online]. dez. 2004, vol.20, no.45 [citado 22 Julio 2007], p.03. Recuperado de http://www.scielo.org.ve/scielo.php?script=sci_arttext\&pid=S101215872004000300002

Richards, G. (2001). Lugares de interés cultural y turístico europeo. Wallingford: CABI Segre, P. (1997). Semiología Urbana. Colombia. Univ. Santa Fe.

Serrano, M. (1982). Teoría de la Comunicación. Madrid.

Silva, A. (2007). Imaginarios Urbanos en América Latina. Urbanismos Ciudadanos. Barcelona: Fundación Antoni Tápies

Thompson, B. (2014) "Memória e exaltação da vida no cemitério monumental". Archivo de la Revista SOCIAIS E HUMANAS, SANTA MARIA, 27 (03): 89 -107.

Vento, E. (2002). La última morada, Ediciones Matanzas, Matanzas.

Zechetto, V. (2002). La danza de los signos. Ecuador: Editorial Abya Yala

Zecchetto, V. (2005). Seis semiólogos en busca del lector: Saussure, Pierce y Barthes, Greimas 


\section{PARA CITAR EL ARTÍCULO INDEXADO.}

García L., Narváez C. \& Erazo J., (2019). Aproximación semiótica para la interpretación del cementerio de Riobamba., revista electrónica Visionario Digital 3(2), 355-374. Recuperado desde: http://www.visionariodigital.org

\section{Ciencia LDigital}

El artículo que se publica es de exclusiva responsabilidad de los autores y no necesariamente reflejan el pensamiento de la Revista Ciencia Digital.

El artículo queda en propiedad de la revista y, por tanto, su publicación parcial y/o total en otro medio tiene que ser autorizado por el director de la Revista Ciencia Digital.
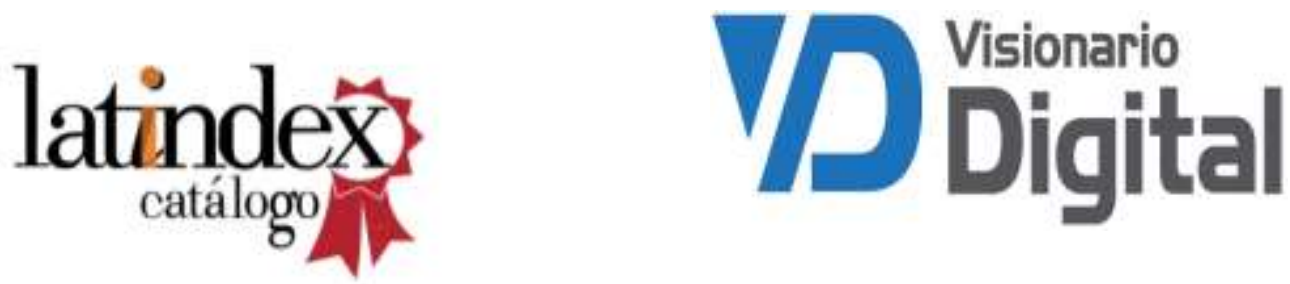